\title{
Research on Urban Logistics Distribution Based on Dynamic Demand
}

\author{
Xuefei Zhang \\ Guangxi University of Science and Technology \\ No.268 Donghuan Road Liuzhou, Guangxi, China
}

\author{
Gengbao Huang \\ Guangxi University of Science and Technology \\ No.268 Donghuan Road Liuzhou, Guangxi, China
}

\begin{abstract}
At present, the problems of high distribution cost and low efficiency in China's logistics distribution link have become the main bottleneck restricting the further development of e-commerce retail industry. Based on the analysis of present situation of logistics distribution, the development of joint distribution operation mode is put forward. This can not only meet the distribution needs of e-commerce customers, but also optimize the last mile resource allocation and distribution, as well as reduce the distribution cost of logistics enterprises.
\end{abstract}

Keywords-Urban logistics distribution; Demand uncertainty; A total of distribution; The electronic commerce

\section{INTRODUCTION}

Logistics distribution process is an indispensable part of the smooth development of e-commerce and plays an important role in all aspects of e-commerce. Distribution is based on collection and distribution. We must take into account the type of goods to be delivered, the place of delivery, the maximum load of vehicles, customer requirements and other factors, make reasonable arrangements to achieve high efficiency and low cost. In logistics distribution, the process of delivery and distribution of all goods mainly includes: collection, that is, the collection of goods from each distribution unit; Distribution, that is, to further consider the different requirements of each customer, the choice of distribution. Finally, taking into account the size, weight and assembly of the goods to be delivered, including the volume, load, current road conditions, distribution routes and other factors of all vehicles at the distribution point, is considered to be. Assign work. Many scholars at home and abroad have conducted a lot of in-depth research on vehicle scheduling, logistics and other work, and obtained some valuable research results.

\section{OVERVIEW OF LOGISTICS TERMINAL DISTRIBUTION}

Urban logistics distribution refers to the logistics activities of transporting, storing, packaging, distributing, loading and unloading goods within the city and delivering the right goods to customers at the right time and place according to the requirements of customers[1-2].The development of urban logistics distribution can not only make the reasonable integration and distribution of urban resources, but also improve the utilization rate of urban resources. The main objectives of urban logistics distribution are: to improve the profitability of logistics enterprises, reduce logistics costs, improve customer service quality, improve customer satisfaction, and promote green logistics.

Logistics distribution is to meet the direct purpose of the end customer distribution activities. Logistics exists in the distribution of all physical goods. It is a series of processes that deliver goods to customers, which is the last mile service in the whole product circulation. Direct contact with consumers. The quality of logistics service directly affects customer satisfaction, so logistics is the most important link in the whole logistics chain. Logistics distribution has the characteristics of dispersed service scope, uncertain demand and declining value added. Therefore, problems such as high product damage rate, uncertain service quality and poor information communication often exist in logistics distribution. In the environment of increasingly fierce e-commerce competition and flat shopping channels, the research on logistics distribution is particularly important and necessary.

\section{CHARACTERISTICS OF URBAN LOGISTICS DISTRIBUTION SYSTEM}

Urban logistics distribution system has three characteristics of openness, complexity and dynamics. The openness, complexity and dynamics of distribution services are reflected in the fact that distribution services are not limited to the inner city, and distribution services become relatively complex due to the influence of external environment.

\section{A. Large conveying capacity, high pressure}

Urban logistics distribution not only needs to transport and distribute goods for various enterprises in the city, but also needs to meet the demand of all urban residents for logistics and distribution services, which increases the number of distribution tasks and not only the number of distribution. It also increases the distribution pressure.

\section{B. Strong agility}

Along with the customer to the logistics service request unceasing enhancement, the logistics distribution service is more and more specialized. Logistics distribution services can only meet the needs of customers, with a strong agile response. They are also sensitive, mobile, and reactive. Flexible logistics vehicles with characteristics will also enhance the agility of urban logistics distribution system. 


\section{Distribution is the main, warehousing as a supplement}

The functions of urban logistics distribution center mainly include transportation, warehousing, distribution, information processing and other logistics functions. Logistics is from the distribution center to all distribution points and then to customers, so as to realize transportation and distribution. Distribution is the most important function of urban distribution center. At the same time, the goods need to be temporarily stored during transshipment. Therefore, the urban logistics distribution system is positioned to give priority to distribution and warehouse as a supplement.

\section{Sustainable development}

Reasonable logistics distribution path planning can reduce unnecessary duplication and cross-transport, reduce the cost of logistics distribution at the same time to alleviate the situation of urban traffic congestion, and reduce energy consumption and urban environmental pollution, for the sustainable development of the city has made a contribution.

\section{THE OPERATION MODE OF JOINT DISTRIBUTION AT THE END OF LOGISTICS}

Final delivery is literally the last part of the entire logistics process, often called the last mile. Its essence is the last part of logistics distribution service chain. Its terminal object is the consumer, the purpose is to deliver goods to the consumer. In the logistics supply chain, there are enterprises responsible for providing goods, enterprises responsible for the transportation of goods and enterprises specializing in warehousing. Clear division of labor between upstream and downstream enterprises. In the whole process, consumers usually have no access to the intermediate service providers in the logistics supply chain, and they have direct access to the final delivery service providers, so the final delivery is the most influential part of the consumer service experience.

Existing e-commerce companies or logistics companies themselves are independent solutions to the problem of terminal distribution, and the main body between them tries to break this traditional thinking with the common distribution theory. Enterprises cooperate with each other in the alliance of terminal logistics. The alliance enterprises divide the distribution area according to the distribution volume and distribution radius, and then combine the advantages of doorto-door distribution and self-service. A multi-terminal public distribution network for electronic distribution is established in this area.

The common point of logistics distribution is that when the distribution of users in a certain area is improved, multiple distribution enterprises carry out unified planning and scheduling for distribution centers. This is a collaborative distribution mode of logistics and distribution services between enterprises to rationalize the overall distribution, reduce logistics costs and provide mutual benefit and win-win convenience. The core of the company is to enrich and strengthen the distribution function[3].The advantage of joint distribution lies in that it is conducive to the effective allocation of distribution resources, makes up for the deficiency of distribution enterprise functions, promotes the improvement of enterprise distribution ability and the expansion of distribution scale, better meets customer needs, improves distribution efficiency, and reduces distribution cost. The disadvantage is that different products, management regulations and management consciousness of different enterprises may bring obstacles from another aspect

\section{A. Logistics terminal distribution problem}

1) Logistics terminal logistics network system planning degree is low: Messenger service is the supplement of national postal service and an important part of urban function. At present, there are many commercial entities in China's express delivery market. In order to quickly occupy the consumer market, many express delivery companies have set up service points in universities and business offices. This kind of blind expansion leads to unreasonable distribution of express logistics network. The utilization rate of some outlets is not high, which often cannot bring better benefits to express enterprises, but will increase the operating cost of enterprises and waste social resources.

2) Express terminal logistics has a negative impact on the sustainable development of cities: Express terminal logistics has the characteristics of small batch, multi-batch, mainly concentrated in the central area of the city. Many express delivery operators are responsible for each other, forming a highly overlapping distribution within the city, which not only wastes their own logistics resources, but also takes up too much urban transportation resources, which has become one of the main incentives for urban transportation companies. Research progress in recent years.

3) Urban logistics land is difficult to guarantee: Logistics land is the space carrier to realize various logistics functions and facilities, and it is responsible for warehousing, transportation, loading and unloading, handling and other functions. At present, Beijing, Shanghai and other large urban agglomerations are highly developed and utilized internally, so it is difficult to obtain new logistics land use indicators. At the same time, due to the relatively low land income of land use units for logistics, local governments tend to control the scale of land use for logistics in land use planning, and tend to use land for office, residential and commercial purposes. Due to the low fiscal revenue that logistics land can achieve and the insufficient contribution of tax to urban development, the government is less willing to transfer logistics land, which indirectly promotes the continuous increase of logistics land rent.

4) Distribution service quality is difficult to guarantee, there is no perfect evaluation index system: Facing the intense competition environment makes electricity or logistics enterprise to end outlets close to send express the response speed of the demand is higher and higher, but due to the lack of professional logistics facilities part of the end of the distribution network using paper archive artificial unloading operations lead to express high damage rate, delayed delivery, delivery time and place do not conform to the requirements of 
the customers, etc., in addition, the Courier company join network terminal logistics distribution mostly, logistics enterprises lack of perfect into the mechanism and operating mechanism in terms of customer satisfaction and the ability to operate the lack of perfect appraisal system [4-5].

5) Primer treatment cannot be guaranteed. In the fierce competition between domestic e-commerce companies and logistics companies, logistics companies are increasingly required to respond quickly to the delivery of sales terminals and have detailed restrictions on the daily basic business volume. At present, the express company's terminal logistics distribution is mostly directly under the network. Followers punish affiliates for failing to complete their daily work or for being slow to respond. The logistics industry has transferred the problem of low timeliness and high cost of terminal distribution to the income of distribution personnel. High fines lead to frequent resignations of logistics personnel at the bottom of logistics enterprises.

\section{B. Develop the logistics terminal joint distribution mode}

Through joint distribution of logistics end links, not only can the distribution efficiency and service capacity of express delivery last mile end logistics be improved, but also the end business cost of logistics enterprises be reduced to realize joint distribution of multi-logistics enterprises. It can avoid repeated setting in the same region, greatly saves social logistics resources, and promotes the improvement of urban traffic conditions and ecological environment.

Through joint distribution of logistics end links, not only can the distribution efficiency and service capacity of express delivery last mile end logistics be improved, but also the end business cost of logistics enterprises be reduced to realize joint distribution of multi-logistics enterprises. It can avoid repeated setting in the same region, greatly saves social logistics resources, and promotes the improvement of urban traffic conditions and ecological environment.

Joint distribution is the concept of enterprise participation and mutual benefit. The key is that each participating enterprise can clearly identify the win-win effect of cooperation on enterprise development and supply chain management. Only in this case, there is a risk of operational information leakage. To solve this problem, it is necessary to establish a perfect information protection mechanism to ensure the security of business information of enterprises and prevent information leakage. Enterprises participating in joint distribution shall sign information confidentiality agreements to ensure that the logistics information within the enterprise team is kept secret from each other so as to avoid information leakage affecting the overall interests.

In the co-distribution mode, a third party establishes a service at the end of a certain geographical range to codistribute the store. On the one hand, it accepts the last mile distribution of different logistics enterprises, realizing the comprehensive integration of final resources such as messenger and service network. For logistics enterprises to solve residential, commercial centralized distribution problems. For example, in 2011, Beijing established the first 15 city 100 service stations covering 100 communities, serving more than 132,000 residents. After the express company sends the package to city 100 , the service desk notifies consumers via SMS platform. Consumers can retrieve the express at any time, or choose to be delivered by the service station. This model takes unified store opening as the platform, improves the complaint rate, helps the rapid development of e-commerce, supports people's increasing personal consumption, and helps realize high-quality community construction.

\section{Optimization principle of logistics terminal distribution}

With the continuous growth of logistics distribution demand, a series of problems such as high end-to-end logistics distribution cost, poor timeliness of distribution, and low logistics distribution satisfaction have increasingly attracted the attention of e-commerce companies and logistics enterprises. Government and consumers. Optimize existing terminal delivery patterns. The following three principles should be satisfied when optimizing the end allocation mode:

1) Customer focus: Terminal allocation is a direct link to the end customer. The quality of terminal service directly affects the customer's e-commerce experience. Therefore, when optimizing the final delivery mode, we must propose an appropriate optimization solution from the customer's perspective to solve this problem.

2) Feasibility principle: The optimization of terminal distribution mode is a practical problem, so when meeting the needs of customers and enterprises, the constraints in the actual situation must also be considered to make the proposed optimization scheme feasible [6]. In other words, terminal distribution optimization solution is a feasible solution under the current technical requirements, laws, regulations and policies.

3) Economic principles: The core problem at the end of the current delivery period is the low utilization of resources, resulting in a high proportion of the cost at the end of the delivery period. Therefore, the final optimization solution also needs to take economic factors into account to minimize the total cost of distribution.

\section{BENEFIT ANALYSIS OF JOINT DISTRIBUTION AT THE END OF LOGISTICS}

The main feature of joint distribution of logistics terminals is to integrate e-commerce and logistics enterprises' after-sales orders, achieve economies of scale and reduce the cost of terminal distribution. By comparing end-to-end public distribution, it can be concluded that end-to-end public distribution has the following advantages:

\section{A. Reduce the number of personnel dispatched}

After the implementation of terminal joint distribution, logistics or e-commerce enterprises do not need to separate the customer delivery in a certain area for distribution, but through the joint distribution center or a third party to achieve joint distribution, in this case, e-commerce is e-commerce. Or reduce e-commerce. Logistics companies need to allocate the required delivery personnel separately. 


\section{B. Reduce investment in fixed assets}

Firstly, the integration of logistics terminal distribution nodes can reduce the investment of fixed assets. After conducting joint distribution at the end, the electricity or express enterprise without the need for a separate set up distribution node at the end, but according to the customer order distribution, based on the integration of existing resources, reasonable layout plan through to the end of the joint distribution node, terminal distribution network can be more perfect, can reduce the investment in fixed assets at the same time, improve service levels.

\section{Reduce environmental pollution}

The adoption of terminal Shared distribution mode mainly reduces the adverse impact on the environment from the following aspects: first, Shared distribution is used to realize the aggregation of customer needs in the same distribution task, thus reducing the mileage of vehicle distribution; Reducing the loading rate of vehicles can reduce the number of transport vehicles under the overall distribution task conditions, reduce the environmental pollution of distribution vehicles, and relieve the traffic pressure of the city.

\section{Reduce delivery mileage}

Realized the scale effect of the terminal distribution link of each express enterprise and gathered the customer demand. With the scheduler's limited service capabilities, a single scheduler can perform scheduling in a relatively small area. Compared with the situation of individual enterprise distribution, the demand points of individual enterprise customers are relatively scattered, so the dispatcher needs to work in a larger area under the condition of certain service capability. The adoption of terminal common mode can reduce dispatcher's allocated mileage, thus reducing allocation costs such as fuel consumption [7].

\section{CONCLUSION}

This paper studies the impact of the explosive growth of shopping on logistics distribution in the context of e-commerce. This paper mainly studies the mode and benefit of terminal public distribution in logistics distribution. With the increase of logistics distribution quantity, terminal distribution has the problems of high cost and low efficiency. This paper proposes to apply the theory of public distribution to terminal distribution, optimize terminal distribution network, and improve the efficiency and service level of terminal distribution. The logistics resources at the end of the city are integrated and uniformly distributed, and the distribution network at the end is zeroed to form the distribution network at the end, thus reducing the overall cost of terminal distribution.

\section{REFERENCES}

[1] Ma Cunrui, Bai Wei, Zhao Xinmiao, Zeng Wei. Research on Optimization of Express Delivery Vehicle Routing[J]. Journal of Transportation Systems Engineering and Information, 2017, 17(04): 182-187.(In Chinese)

[2] ZHOU Lin, LIN Yun, WANG Xu, ZHAO Quan-wu. Optimization of online multi-capacity terminal location and multi-vehicle path integration for online shopping $[\mathrm{J}]$. Computer Integrated Manufacturing Systems, 2016, 22(04): 1139-1147.(In Chinese)

[3] Zhu Lin. Research on multi-center dynamic vehicle routing problem with time window under stochastic demand [D]. Dalian Maritime University, 2017.(In Chinese)

[4] Liu R, Tao Y, Hu Q, et al. Simulation-based optimisation approach for the stochastic two-echelon logistics problem[J]. International Journal of Production Research, 2017, 55(1):187-201.

[5] Mirzaei S, Sanne Wøhlk. Erratum to: A Branch-and-Price algorithm for two multi-compartment vehicle routing problems[J]. EURO Journal on Transportation and Logistics, 2017, 6(2):185-218.

[6] Altintaș H, ÖZNUR ATEȘ, Birteksöz S, et al. Study on Logistics Center Site Selection of Jilin Province[J]. Journal of Software, 2012, 7(8):35-9.

[7] Zhu S, Dekker R, Jaarsveld W V, et al. An Improved Method for Forecasting Spare Parts Demand using Extreme Value Theory[J]. European Journal of Operational Research, 2017, 261(1). 